|| ISSN(online): 2589-8698 || ISSN(print): 2589-868X ||

International Journal of Medical and Biomedical Studies Available Online at www.ijmbs.info

NLM (National Library of Medicine ID: 101738825)

Index Copernicus Value 2020: 79.44

Volume 5, Issue 12; December: 2021; Page No. 39-40

\title{
A DESCRIPTIVE STUDY OF BACTERIOLOGICAL SPECTRUM OF ORTHOPEDIC IMPLANT INFECTION IN CLOSED FRACTURES
}

\author{
${ }^{1 *}$ Dr Sawai Singh, ${ }^{2} \mathrm{Dr}$ Lokesh Soni \\ ${ }^{1}$ Senior Resident, Department of Orthopaedic Govt Medical College Barmer \\ ${ }^{2}$ Senior Resident Department of Orthopaedic, Medical College Bikaner
}

Article Info: Received 11 October 2021; Accepted 29 November 2021

DOI: https://doi.org/10.32553/ijmbs.v5i12.2334

Corresponding author: Dr Sawai Singh

Conflict of interest: No conflict of interest.

\section{Abstract}

Background: Surgical Site Infection (SSI) is defined as pain associated with erythema, induration, local tenderness, pus discharge or any culture positive ornegative discharge from a surgically created wound.

Methods: Hospital based Descriptive type of Observational study conducted on Patients in the department of Orthopaedics.

Results: Total $5.00 \%$ patients have wound infection. Gram positive $80.00 \%$ patients have found with Staph. Aureus and Gramnegative $20.00 \%$ patients have found with Pseudomonas.

Conclusion: Infection in closed fractures with implants was quite high. The adverse outcome of SSIs related to a clean orthopedic surgical procedure can be associated with significant morbidity, cost, and even mortality.

Keywords: Infection, SSI, Fracture

\section{Introduction}

The serious consequences imposed on patients who developed SSI determine the need for efforts to create strategies for the prevention ofthis infection. One of the strategies used is the determination of risk factors, which allows identifying clinical situations or conditions that predispose to the development of SSI. In this sense, the identification of risk factors for SSI contributes to the early adoption of nursing interventions that aim to minimize this type of postoperative complication. ${ }^{1}$

SSI is a great disaster in terms of financial burden on the hospital resources, morbidity and mortality. Being a preventable condition, SSI frequencies are continuously surveyed throughout the world to help reduce its incidence. So the rationale of the study is to monitor the SSI rate in orthopaedic implant surgeries and its common causative organisms in our population undergoing orthopaedic implant surgery and if the frequencies are found significantly higher than other studies, then device measures to help reduce its frequency and thus decrease both financial burden of the state and morbidity and mortality of the patients. ${ }^{2-4}$

This studywill also provide us fresh local data regarding bacteriology of SSI of orthopaedic implants surgery and will guide us in setting future recommendation for rational use of antibiotics.

\section{Materials and Methods}

Hospital based Descriptive type of Observational study

Inclusion Criteria -

- Closed fracture cases

- Either gender

- In age groups admitted from 18-70 years

- Elective implant surgery

- Emergency implant surgeries

Exclusion Criteria-

- Pregnancy

- Periprosthetic fractures

- Associated major visceral injury

- Soft tissue surgery,

- Open fractures needing external fixation devices,

- Pathological fractures

- Patient with pre-existing cardiac/pulmonary/renal disease

Results 
Table 1: Microorganism wise distribution of the study

\begin{tabular}{|c|c|}
\hline & No of cases \\
\hline NIL & $95(5.00 \%)$ \\
\hline Pseudomonas & $1(1.00 \%)$ \\
\hline Staph. Aureus & $4(4.00 \%)$ \\
\hline Total & 100 \\
\hline
\end{tabular}

Total $5.00 \%$ patients have wound infection. Gram positive $80.00 \%$ patients have found with Staph. Aureus and Gram negative $20.00 \%$ patients have found with Pseudomonas.

\section{Discussion}

Implant supported infection is an unsolved problem in the development of orthopaedics. Infections occurs even through orthopaedists perform thoroughly clean procedures during surgery and patients are strictly managed before and after surgery. Infection is a very important problem in the orthopaedic surgery because of its continuing incidence, clinical importance and serious sequelae, the treatment being very difficult and expensive (for example, the treatment of an infected hip prosthesis costs twice as much as an aseptic revision and six times as much as the primaryreplacement). Rates of infection have been reduced by antibiotic prophylaxis, but the increasing number of implants used means that there are still many patients affected each year. Implants are avascular and therefore antibiotics can reach them only by diffusion from the surrounding tissues. Infection involving an implant cannot be cured simply with antibiotics and it often necessitates the surgical removal of the implant. Phillips $(2003)^{5}$ et al reported that among patients who had primary total hip replacement, $0.2 \%$ of 58521 had a deep infection duringthe first 26 postoperative weeks.

\section{Conclusion}

Infection in closed fractures with implants was quite high. The adverse outcome of SSIs related to a clean orthopedic surgical procedure can be associated with significant morbidity, cost, and even mortality. The patient's functional status may also be adversely affected by an orthopedic SSI. Staphylococcus aureus was the commonest organismisolated from the infected cases

\section{References}

1. Sabir MR, Iqbal MZ, Malik MR. Surgical Site Infections in Orthopedic Patients; a public health dilemma. Pak J Med HealthSci 2010;4(1):143-8.

2. Anderson DJ, Podgorny K, Berríos-Torres SI, Bratzler DW, Dellinger EP, Greene L, et al. Strategies to prevent surgical site infections in acute care hospitals. Infect Control Hosp Epidemiol 2014; 35(s2): s66-s88.

3. Engemann JJ, Carmeli Y, Cosgrove SE, Fowler VG, Bronstein MZ, Trivette SL, et al. Adverse clinical and economic outcomes attributable to methicillin resistance among patients with Staphylococcus aureus surgical site infection. Clin Infect Dis 2003;36: 592-8.

4. Lofti CJ. Risk factors for surgical-site infections in head and neck cancer surgery. Otolaryngol Head Neck Surg 2008;138:74-80.

5. Savvidou OD, Kaspiris A, Trikoupis I, Kakouratos $G$ et al.Efficacy of antimicrobial coated orthopaedic implants on the prevention of periprosthetic infections: a systematic review and meta-analysis. J Bone Joint Infect 2020;5:212-22. 